\title{
COMPARATIVE EVALUATION OF ROTAHALER WITH ACCUHALER USED FOR DELIVERY OF COMBINATION DRUGS (FLUTICASONE AND SALMETEROL) IN CHILDHOOD BRONCHIAL ASTHMA
}

\author{
Suddapalli Sivaram Prasad ${ }^{1}$
}

${ }^{1}$ Associate Professor, Department of Paediatrics, Katuri Medical College and Hospital, Guntur.

\begin{abstract}
$\overline{\text { AIM }}$

To compare efficacy of Rotahaler and Accuhaler using combination drugs of fluticasone and salmeterol in childhood bronchial asthma.

MATERIALS AND METHODS

A prospective study was planned with 60 patients of both sexes in the age group of 5-12 years, who reported to Asthma Clinic and fulfilled inclusion and exclusion criteria after parental consent. All patients included in the trial were initially entered into runin period of 2 weeks, during which a record was maintained of their clinical parameters and allowed to take their prescribed medication. At the end of run-in period the baseline symptoms and signs of asthma, PFT, amount of rescue medication and nocturnal awakening due to asthma symptoms were recorded. After run-in period, based on computer generated random numbered tables patients were randomized to receive either Rotahaler or Accuhaler with same combination medication. Statistical analysis was performed to compare both groups.
\end{abstract}

\section{CONCLUSION}

The present study demonstrated that there is no significant difference between Rotahaler and Accuhaler in clinical and PFT improvements in childhood bronchial asthma.

\section{KEYWORDS}

Asthma, Children, Pulmonary Function Test (PFT), Rotahaler, Accuhaler, Fluticasone, Salmeterol, DPI.

HOW TO CITE THIS ARTICLE: Suddapalli Sivaram Prasad. “Comparative Evaluation of Rotahaler with Accuhaler used for Delivery of Combination Drugs (Fluticasone and Salmeterol) in Childhood Bronchial Asthma." Journal of Evolution of Medical and Dental Sciences 2015; Vol. 4, Issue 96, November 30; Page: 16160-16162, DOI: 10.14260/jemds/2015/2371

\section{INTRODUCTION}

This study was conducted for comparative evaluation of Rotahaler and Accuhaler using combination drugs of fluticasone and salmeterol in childhood bronchial asthma. Clinical PFT, use of rescue medication and nocturnal awakening due to asthma symptoms was assessed and compared between both groups.

\section{MATERIALS AND METHODS}

This study was conducted in Asthma Clinic of the pediatric OPD, at Katuri Medical College and Hospital, Guntur, between 2012 and 2013. A prospective study was planned with 60 patients of both sexes in the age group of 5-12 years, who reported to Asthma Clinic and fulfilled inclusion and exclusion criteria after parental consent. All patients included in the trial were initially entered into run-in period of 2 weeks, during which a record was maintained of their clinical parameters and allowed to take their prescribed medication. At the end of run-in period, the baseline symptoms and signs of asthma, PFT, amount of rescue medication and nocturnal awakening due to asthma symptoms were recorded.

After run-in period, based on computer generated random numbered tables, patients were randomized to receive either Rotahaler or Accuhaler with same combination medication.

Financial or Other, Competing Interest: None.

Submission 10-11-2015, Peer Review 11-11-2015,

Acceptance 23-11-2015, Published 28-11-2015.

Corresponding Author:

Dr. Suddapalli Sivaram Prasad,

Flat No: 4, First Floor

Amrutha Apartments,

Veterinary Colony Road, No. 5,

Vijayawada- 5, Andhra Pradesh, India.

E-mail: suddapalli2000@yahoo.com

DOI:10.14260/jemds/2015/2371
Blinding could not be done because of nature of the trial However, all precautions were taken for good study. Various parameters like symptom score (E.g. cough, breathlessness); clinical score (e.g. Wheeze, use of accessory muscles); PFT (E.g. FEV1, FVC, PEFR); nocturnal awakening (E.g. number of nights in a week patient awakened due to asthma symptoms as per history); use of rescue medication (Number of salbutamol puffs patient required per week) were used to assess efficacy of device at monthly intervals for two months. Statistical analysis was performed between data of both groups.

\section{RESULTS}

In this study, a total of 60 children with moderate persistent asthma fulfilled inclusion and exclusion criteria and included in the study. Out of 60 children, 56 children completed three visits and 4 children dropped out from the study. Out of total 56 children studied, 40 subjects $(71.4 \%)$ were male and 16 subjects $(28.6 \%)$ were female. There were 37 patients $(66 \%)$ in the age group $5-8$ years and 19 patients $(44 \%)$ in the age group of 9-12 years. There are two groups, which underwent intervention in the form of fluticasone propionate and salmeterol inhalation by either Rotahaler or Accuhaler.

Before intervention, baseline characters of both groups were compared and analyzed. There was no statistically significant difference between two groups in relation to age, weight and height. Before intervention, there was no statistically significant difference between two groups for baseline characters like symptom score (E.g. cough, breathlessness); clinical score (E.g., wheeze, use of accessory muscles); PFT (E.g. FEV 1 , FVC, PEFR); nocturnal awakening (Number of nights in a week patient awakened due to asthma symptoms as per history); and use of rescue medication (Number of salbutamol puffs patient required per week). There is no statistically significant difference between Rotahaler group and Accuhaler group at first review after one month and second review after two months post intervention 


\begin{tabular}{|c|c|c|c|c|c|c|c|c|c|}
\hline \multirow{2}{*}{ Sl.No. } & \multirow{2}{*}{ CHARACTER } & \multicolumn{3}{|c|}{ Rotahaler Group } & \multicolumn{3}{c|}{ Accuhaler Group } & \multirow{2}{*}{ P-value } & \multirow{2}{*}{ SIGNIFICANCE } \\
\cline { 3 - 9 } & & Mean & SD & S.Err & Mean & SD & S.Err & & \\
\hline 1 & Symptom score & 1.033 & 0.629 & 0.115 & 0.692 & 0.618 & 0.121 & $>0.005$ & Not sig \\
\hline 2 & Clinical score & 0.433 & 0.774 & 0.141 & 0.090 & 0.382 & 0.063 & $>0.005$ & Not sig \\
\hline 3 & FEV1 & 93.26 & 9.447 & 1.725 & 92.69 & 9.507 & 1.864 & $>0.005$ & Not sig \\
\hline 4 & FVC & 84.56 & 9.171 & 1.674 & 84.13 & 11.25 & 2.206 & $>0.005$ & Not sig \\
\hline 5 & PEFR & 91.76 & 13.73 & 2.506 & 95.32 & 14.65 & 2.429 & $>0.005$ & Not sig \\
\hline 6 & Nocturnal awakening & 1.066 & 0.907 & 0.166 & 0.538 & 0.859 & 0.169 & $>0.005$ & Not sig \\
\hline 7 & Rescue medication & 2.400 & 2.191 & 0.400 & 0.230 & 1.704 & 0.334 & $>0.005$ & Not sig \\
\hline \multicolumn{8}{|c|}{ Table 1: Comparison of Rotahaler and Accuhaler (1 seview $)^{\text {st }}$}
\end{tabular}

\begin{tabular}{|c|c|c|c|c|c|c|c|c|c|}
\hline \multirow{2}{*}{ Sl.No. } & \multirow{2}{*}{ CHARACTER } & \multicolumn{3}{|c|}{ Rotahaler Group } & \multicolumn{3}{c|}{ Accuhaler Group } & \multirow{2}{*}{ P-value } & \multirow{2}{*}{ SIGNIFICANCE } \\
\cline { 3 - 9 } & & Mean & SD & S.Err & Mean & SD & S.Err & & \\
\hline 1 & Symptom score & 0.433 & 0.626 & 0.114 & 0.192 & 0.402 & 0.079 & $>0.005$ & Not sig \\
\hline 2 & Clinical score & 0.100 & 0.403 & 0.074 & 0.090 & 0.382 & 0.063 & $>0.005$ & Not sig \\
\hline 3 & FEV1 & 95.46 & 7.464 & 1.363 & 93.26 & 8.637 & 1.694 & $>0.005$ & Not sig \\
\hline 4 & FVC & 87.03 & 9.590 & 1.751 & 83.92 & 10.32 & 2.024 & $>0.005$ & Not sig \\
\hline 5 & PEFR & 95.80 & 11.74 & 2.140 & 98.84 & 15.65 & 2.029 & $>0.005$ & Not sig \\
\hline 6 & Nocturnal awakening & 1.300 & 0.651 & 0.119 & 0.231 & 0.652 & 0.128 & $>0.005$ & Not sig \\
\hline 7 & Rescue medication & 0.733 & 1.701 & 0.310 & 0.653 & 1.719 & 0.337 & $>0.005$ & Not sig \\
\hline \multicolumn{8}{|c|}{ Table 2: Comparison of Rotahaler and Accuhaler (2 seview $)^{\text {st }}$}
\end{tabular}

\section{DISCUSSION}

In the present day scenario, bronchial asthma is a leading cause of morbidity in our society and more so in pediatric age group. ${ }^{1}$ there have been revolutionary changes in the management of bronchial asthma during past few years. Aerosol therapy has come to stay as the backbone of therapy. Acute attacks in the pediatric age group requiring hospital management and nebulization is primary mode of drug delivery to the lungs., ${ }^{2}$ inhalation steroids with long acting bronchodilator indicated in moderate persistent and severe persistent asthma.

Breath activated inhaler devices may have different in vitro deposition characteristics for delivery of same drug. Our study aimed at comparative evaluation of Rotahaler and Accuhaler using drugs fluticasone propionate 100 Micrograms) and salmeterol (50 Micrograms) in patients of 512 age group suffering from moderate persistent asthma. Both of them are dry powder devices.

A total of 56 subjects were evaluated after random allocation to either Rotahaler group or Accuhaler group. Before random allocation, one month after random allocation and two months after random allocation various disease parameters like symptom score, clinical score, PFT, nocturnal awakening due to asthma symptoms and rescue medication required recorded. Data from baseline, one month after application of medication and two months after application of medication was analyzed for both groups and compared There was no statistically significant difference between both groups, indicating that both of them are equally effective.

Similar results were published by Pieter and Associates. ${ }^{3}$ There is controversy about efficacy of Rotahaler versus MDI. Some authors conclude that both Rotahaler and MDI are equal in efficacy. For example, Singh M and Kumar L from PGI Chandigarh conclude that MDI and Rotahaler have equal efficacy in anti-inflammatory therapy of bronchial asthma in children., ${ }^{4}$ whereas others conclude double dose of drugs in DPI is required to achieve same efficacy when compared with MDI. For example Chhabra SK from Delhi University conclude that bronchodilator effect is superior in MDI and a double dose of drug is required to achieve the same results. ${ }^{5}$

In our study, both Rotahaler and Accuhaler are effective in producing good clinical response and PFT improvement and there was no significant difference between Rotahaler and Accuhaler groups in clinical response and PFT improvement.
No drug-induced side effects were noticed in our study. One Accuhaler developed mechanical problem during the study. A total of $96 \%$ of patients in Rotahaler group and $93 \%$ of patients in Accuhaler group demonstrated correct technique after one month. However, there is significant difference in price of both devices.

Similar results were found by Mehta R and others in their study, Comparison of the Pharmacokinetics of Salmeterol and Fluticasone Propionate 50/100 $\mu$ g delivered in combination as a dry powder via a capsule-based inhaler and a multi-dose inhaler. ${ }^{6}$ However, Thomus $\mathrm{M}$ and Willium AE in their study titled 'Are outcomes the same with all dry powder inhalers?' indicate that different levels of asthma control is possible with different devices even with same chemical entity. ${ }^{7}$

\section{CONCLUSION}

Both DPI devices of Rotahaler and Accuhaler are very effective in producing clinical and PFT improvement. However, there is no significant difference between them in efficacy. Technique of inhalation can be easily and correctly mastered by majority of children for both DPI. Further research is considered as essential to study the efficacy and other differences between these two devices, as present study was limited to only efficacy and sample size was small.

\section{BIBLIOGRAPHY}

1. Vandane Bathra, Sathi GR, Sachdeva HP. Comparative efficacy of jet nebulizer and metered-dose inhaler with spacer device in the treatment of acute asthma: Ind Ped 1997;34.

2. Pederson S. Choice of Inhalation Therapy in Pediatrics: Ero Resp Rev 1994;4:15-68.

3. Pieters WR, Stallaert RA, Prins J et al. A study on The Clinical Equivalence and Patient Preference of Fluticasone Propeonate (250 Micrograms) twice daily via Discus/Accuhaler inhaler or the Diskhaler inhaler in adult asthmatic patients. J Asthma 1998;35(4):337-45.

4. Singh M, Kumar L. Randomised comparition of a Dry power inhaler and Metered-dose inhaler with spacer in management of children with asthma. Indian Ped 2001 Jan;38(1):24-8.

5. Chhabra SK. Comparison of Salbutamol Dry powder Aerosol with Pressurized aerosol. Indian J Chest Dis Allied Sci 1993 Oct-Dec;35(4):163-6. 
6. Mehta R, Riddell K, Gupta A, Louey MD, Chan RH. Comparison of the Pharmacokinetics of Salmeterol and Fluticasone Propionate 50/100 $\mu$ g Delivered in Combination as a Dry Powder Via a Capsule-Based Inhaler and a Multi-Dose Inhaler. Clin Drug Investig 2015 May;35(5):319-26.
7. Thomus M, Willium AE. Are outcomes the same with all dry powder inhalers? Int J Clin Pract Suppl 2005 Dec;(149):33-5. 